\title{
ANÁLISE DA ARBORIZAÇÃO VIÁRIA DO BAIRRO DE PETRÓPOLIS, NATAL, RN: UMA ABORDAGEM PARA DIAGNÓSTICO E PLANEJAMENTO DA FLORA URBANA
}

\author{
Theomara Ottoni Batista dos Santos ${ }^{12}$, Carolina Maria Cardoso Aires Lisboa ${ }^{3}$, Fabíola Gomes de Carvalho ${ }^{4}$
}

\section{RESUMO}

A arborização viária é uma importante ferramenta para o planejamento urbano por prover benefícios sociais, econômicos e ambientais que proporcionam uma melhor qualidade de vida, devendo estar inserida nos programas, planos e projetos de gestão urbana. Para que haja sucesso nesse processo, é necessário um adequado conhecimento das características e das condições ambientais, uma vez que a multiplicidade de fatores relativos ao espaço artificial torna complexa esta tarefa. $\mathrm{O}$ presente trabalho ocupa-se do levantamento qualiquantitativo da arborização viária das principais vias do bairro de Petrópolis, em Natal-RN, utilizando-se método do tipo censo. Foram levantados 206 indivíduos, num total de 38 espécies, 35 gêneros e 17 famílias, sendo Fabaceae a família mais representativa, com 32,5\% do total de espécimes, e a espécie mais frequente o jambeiro (Syzygium malaccense) com 20,9\%. As espécies exóticas detêm 63,2\% de representação e as nativas apenas 36,8\%. Dentre estas últimas, apenas 13,2\% são nativas regionais. O bairro apresenta um índice de 70 indivíduos/km de via percorrida. Diretrizes em relação ao manejo das espécies, às suas características ideais e à gestão de um Plano de Arborização sustentável são apresentadas.

Palavras-chave: inventário florístico, planejamento urbano, árvores nativas regionais, diretrizes de manejo.

\section{ANALYSIS OF STREET ARBORIZATION FROM PETRÓPOLIS NEIGHBORHOOD, NATAL, RN: AN APPROACH TO DIAGNOSIS AND PLANNING OF URBAN FLORA}

\section{ABSTRACT}

A street arborization is an important tool to the urban planning for providing social, economic and enviromental benefits that provide a better life quality, being worth to be inserted in programs, plans and projects of urban management. To reach success in this proccess is necessary an adequated knowledge of characteristics and enviromental conditions, once the multiplicity of relative factors to the artificial space turns such task quite complex. The present work occupies itself of the qualiquantitative research of the street arborization of the main roads from the Petropólis neighborhood, in Natal-RN, using, as method, the census. It's been researched 206 individuals, in a total of 38 species, 35 genders and 17 families, being the Fabaceae the most representative, with $32.5 \%$ of the total of species, and the more often specie was the jamb tree (Syzygium malaccense) with $20.9 \%$. The exotic species have $63.2 \%$ of representation and the natives just $36.8 \%$. Among these, just $13.2 \%$ are regional native trees. The neighborhood shows a number of 70 individuals $/ \mathrm{km}$ of traveled road. Guidelines about the species handling, their ideal characteristics and the management of a sustaintable Arborization Plan are presented.

Keywords: floristic inventory, urban planning, regional native trees, handling guidelines.

\footnotetext{
${ }^{1}$ Bióloga, mestre em Ciências Biológicas/UFRN, Natal-RN, theomara.ottoni@yahoo.com.br

${ }^{2}$ Data recebimento: 25/10/2011 - Data de publicação: 15/12/2012

${ }^{3}$ Bióloga, mestre em Ciências Biológicas/UFRN. Setor de Projetos e Planejamento Urbano e Ambiental da Secretaria Municipal de Meio Ambiente e Urbanismo, Natal-RN, carolisboabio@yahoo.com.br.

${ }^{4}$ Professora do Instituto Federal de Educação Tecnológica do Rio Grande do Norte, Natal-RN, fgcarvalho@cefetrn.edu.br.
} 


\section{INTRODUÇÃO}

A arborização urbana proporciona, dentre outros benefícios, a manutenção equilibrada e harmônica das espécies arbóreas com o meio citadino a fim de adequar suas características peculiares com o entorno construído, evitando-se danos socioambientais e econômicos. Dessa forma, apresenta-se como uma importante ferramenta para o planejamento urbano, por prover benefícios que proporcionam uma melhor qualidade de vida local, devendo, portanto, estar inserida nos programas, planos e projetos de gestão urbana.

Seu desenvolvimento ocorreu de forma a atenuar os problemas típicos do processo de urbanização desordenado e acelerado das grandes cidades, dando lugar ao ambiente construído e a uma consequente perda de ecossistemas naturais. Dentre os benefícios da arborização urbana, pode-se destacar:

- Social - Proporciona conforto ambiental, lazer nos bosques e nas praças, além de ambiente para descanso e recreação; contribui com o bom aspecto estético-visual, quebrando a monotonia cinza dos monumentos arquitetônicos com o colorido das folhas, frutos e flores.

- Econômico - Gera valorização imobiliária e atrai turistas devido ao conforto e beleza estética.

- Ambiental - Oferece sombra para pedestres, moradias, estabelecimentos comerciais e veículos; contribui para a regulação microclimática por abrandar o processo de aquecimento e atenuar ilhas de calor devido à interceptação de até 98\% da radiação solar pelas árvores (HEISLER, 1974 apud GREY e DENEKE, 1978) e à taxa de evapotranspiração de até $400 \mathrm{~L}$ diários, que aumenta a umidade do ar (GREY e DENEKE, 1978); purifica o ar devido à absorção do gás carbônico e liberação do oxigênio; fornece flores e frutos, além de abrigo à fauna; ameniza a poluição sonora; previne a erosão do solo em áreas não calçadas; e evita o deslizamento de encosta através da fixação das raízes no solo.

A arborização viária é um dos elementos vegetados dos ecossistemas urbanos capazes de integrar espaços livres, áreas verdes e remanescentes florestais, conectando-os de forma a colaborar com a biodiversidade (MENEGHETTI, 2003). Ruas bem arborizadas também podem reter até $70 \%$ da poeira em suspensão (BERNATZKY, 1980 apud GREY e DENEKE, 1978), e uma fila de árvores numa via pode reduzir os elementos particulados em até 25\% (WOOD, 1979 apud GREY e DENEKE, 1978).

Entretanto, para que haja sucesso no processo de arborização viária, é necessário um adequado conhecimento das características e das condições ambientais, devido à multiplicidade de fatores relativos ao espaço artificial. Assim, a escolha de uma árvore deve ser planejada e baseada em critérios técnicos, associando as exigências da planta com as condições oferecidas pelo local de plantio, de maneira que haja compatibilização com obras de infraestrutura urbana como a pavimentação de ruas e passeios, o saneamento, a eletrificação e a comunicação (MILANO, 1984; MEDEIROS e DANTAS, 2007). Deve-se optar também pela utilização de espécies que não causem danos à saúde da população, seja pela presença de estruturas nocivas, como espinhos, ou por conterem substâncias alergênicas que causem irritações (SOUZA et al., 2011), além do uso diversificado das espécies vegetais tanto por motivos estéticos

ANÁLISE DA ARBORIZAÇÃO VIÁRIA DO... 
quanto pela preservação da fauna e da própria diversidade vegetal (BRUN et al., 2007).

Uma das ferramentas fundamentais para planejamento e diagnóstico da cobertura arbórea das cidades é o inventário de arborização urbana. Silva (2008) indica que a maior parte dos censos arbóreos revela um predomínio de espécies exóticas, várias dessas com potencial invasor. Argumenta ainda que o fato de uma cidade não possuir identidade arbórea pelo escasso uso de espécies nativas locais pode inclusive afastar turistas que se interessariam por peculiaridades da região.

Considerando a importância de conservar e valorizar a biodiversidade local em espaços urbanos, é necessário utilizar o conceito de espécies nativas regionais defendido por Isernhagen et al. (2009). Dentre as vantagens no uso dessas espécies na arborização urbana, cita-se a maior resistência a pragas; a criação de um banco genético para a conservação ex-situ; a minimização do risco de uso de espécies exóticas invasoras (BIONDI e LEAL, 2008); a criação de uma nova percepção do espaço urbano por parte dos habitantes ao formar conjuntos que lembrem a paisagem original da região, contribuindo na re-educação para a valorização da biodiversidade no ambiente urbano (REIS et al., 2003); o uso de espécies nativas em processo de extinção como forma complementar de conservação; e, a formação de corredores ecológicos, especialmente para aves nativas e migratórias (ISERNHAGEN et al., 2009).

Porém, a existência de espécies nativas de flora e fauna na malha urbana pode ser inviabilizada em alguns casos, visto que esse ambiente pode dificultar alguns processos biológicos naturais como deslocamentos, busca por alimentos e reprodução, podendo inclusive levar a extinções locais. Por isso, é imprescindível definir, no planejamento da flora urbana, possíveis locais que aumentam a permeabilidade da matriz da paisagem, como fragmentos naturais, corredores ou trampolins ecológicos (ISERNHAGEN et al., 2009), que na cidade de Natal, Rio Grande do Norte, estão na forma de Zonas de Proteção Ambiental (ZPAs), unidades de conservação, remanescentes de dunas e demais áreas verdes no espaço urbano (LISBOA et al., 2011).

Apesar disso, a percepção ambiental dos benefícios da arborização ainda é muito restrita pela maior parte da população. O benefício mais destacado é o estético, em virtude da aparência direta e imediatamente perceptível do estado fenológico das árvores no decorrer das estações do ano (MADRUGADA et al., 2007). Pode-se dizer, então, que a arborização urbana apresenta, dentro do sistema de infraestrutura citadino, uma função não apenas paisagística, que se preocupa em manter o bom aspecto visual, mas também funciona como um recurso de manutenção do bem-estar social, ambiental e econômico, como também de conservação da flora local.

Diante do exposto, o presente trabalho tem como objetivo principal propor diretrizes para o manejo da flora urbana do bairro de Petrópolis, em Natal$\mathrm{RN}$, através da análise do inventário arbóreo de vias públicas, bem como oferecer uma base de dados para auxiliar no plano de gestão e manejo do referido bairro.

Theomara Ottoni Batista dos Santos et al. 


\section{MATERIAL E MÉTODOS}

\section{Caracterização da área de estudo}

O município de Natal, fundado em 25 de dezembro de 1599, está localizado na zona homogênea do litoral oriental do Rio Grande do Norte, entre os paralelos $36^{\circ} 42^{\prime} 53^{\prime \prime}$ e $37^{\circ} 15^{\prime} 11^{\prime \prime}$ ' de latitude sul e entre os meridianos $38^{\circ} 35^{\prime} 52^{\prime \prime}$ e $34^{\circ} 58^{\prime} 03^{\prime \prime}$ de longitude oeste (Figura 1). Abrange uma área total de 16.265 hectares e está dividida em quatro zonas administrativas: norte, sul, leste e oeste. Limita-se ao norte com o município de Extremoz, ao sul com os municípios de Parnamirim e Macaíba, a oeste com o município de São Gonçalo do Amarante, a leste com o Oceano Atlântico. Assim como nos demais centros urbanos, observam-se no município conflitos no uso da terra que, em geral, acabam por gerar perda de áreas verdes para usufruto humano, declínio na riqueza de espécies nativas, perda e fragmentação de habitats, extinções locais e introdução de espécies exóticas (RAMALHO e PIMENTA, 2010; LISBOA et al., 2011).

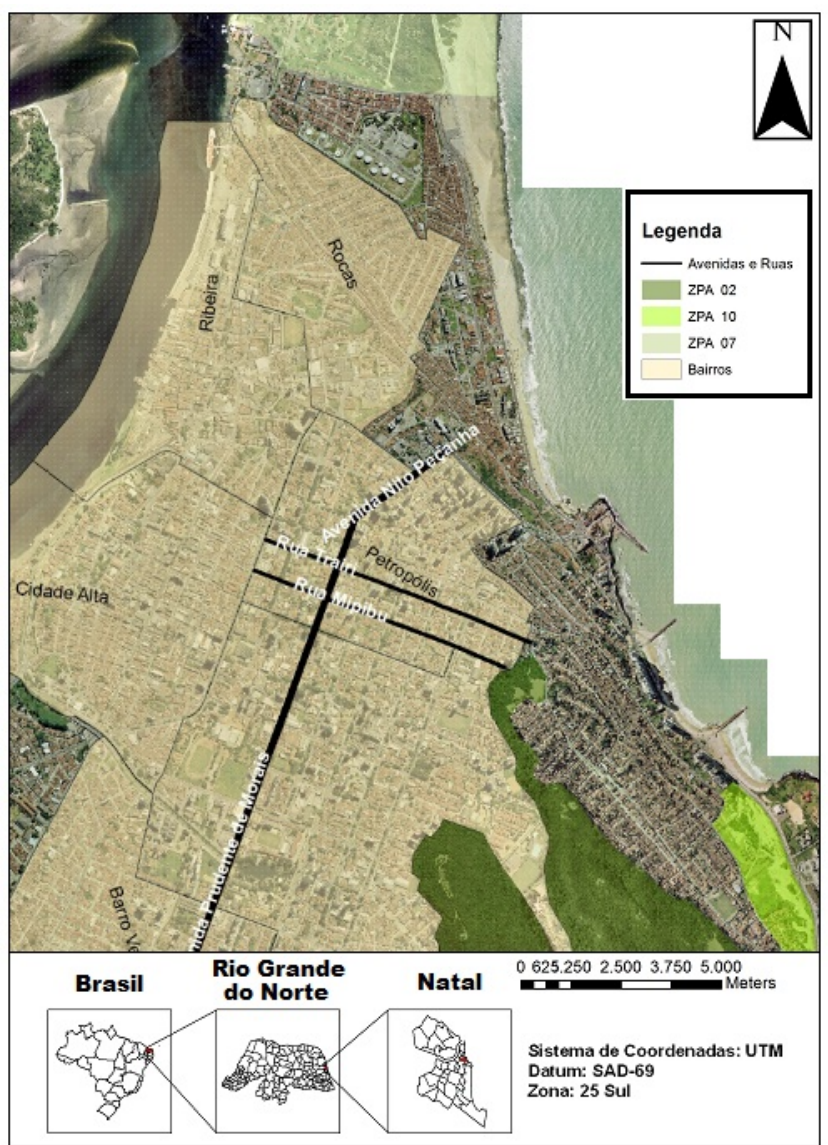


FIGURA 1. Localização das vias e avenidas percorridas no Bairro de Petrópolis, Natal/RN.

O bairro de Petrópolis está inserido na zona adensável da cidade, na região administrativa leste, relativamente próximo às Zonas de Proteção Ambiental (ZPAs) 2, 7 e 10 (Figura 1), com área de 78,43 ha, uma densidade demográfica de 87,96 hab/ha em 2009 e todas as vias asfaltadas (NATAL, 2010). Foi o terceiro bairro a ser criado e referido, na época, como modelo por ter apresentado o primeiro plano de urbanização sistematizado, que abrangia preocupações com o conforto ambiental e o bem-estar social e com um padrão de avenidas largas encontrado em poucos bairros da cidade. Embora o crescimento urbano tenha alterado sua estrutura e dinâmica ao longo dos anos, ainda predominam exemplares arbóreos antigos nas principais vias de acesso ao bairro.

\section{Procedimentos Metodológicos}

O bairro de Petrópolis foi subdividido em espaços amostrais seguindo a metodologia proposta por Grey e Deneke (1978), que recomenda uma representação da área amostral entre 5 a $15 \%$, dependendo do tamanho do bairro e da viabilidade de levantamento dos dados. Como apenas vias públicas foram analisadas, a porcentagem amostral foi representada a partir de trechos de ruas e avenidas, que apresentam um elevado grau de arborização e grandes extensões, ou seja, ligam as duas extremidades limites do bairro.

A seleção das vias públicas foi aleatória, sendo elas a Av. Marechal Deodoro da Fonseca, Av. Prudente de Morais junto com o prolongamento da Av. Nilo Peçanha e a Rua Mipibu, que somam $2.066 \mathrm{~m} \mathrm{e}$ correspondem a $20 \%$ da extensão total das vias do bairro. Quanto à seleção dos exemplares, considerou-se aqueles com diâmetro a altura do peito (DAP, medido a ca. de 1,30 $\mathrm{m}$ de altura) $\geq 5$ cm. Para a identificação das espécies seguiu-se as literaturas especializadas (LORENZI 2002a, 2002b; LORENZI et al., 2003).

O levantamento dos dados foi realizado no mês de agosto de 2010. O método adotado para o inventário qualiquantitativo dos espécimes arbóreos foi do tipo censo, realizado a partir do formulário proposto por Silva Filho (2002), com modificações. Algumas características das espécies foram levantadas, como origem, distribuição, endemismo e se podem ser consideradas potencialmente invasoras e/ou nocivas à saúde, tendo em vista a influência que a arborização urbana pode propiciar à conservação da biodiversidade e à saúde da população. Em relação à origem das espécies, seguiu-se as proposições de Isernhagen et al. (2011), que considerou nativa aquelas espécies encontradas em outros ecossistemas brasileiros exceto o da região em estudo; exótica as de ecossistemas não encontrados no Brasil; e nativas regionais para aquelas espécies que ocorrem nos ecossistemas naturais da cidade, geralmente compostos por dunas e restingas. Com base em levantamentos florísticos em áreas protegidas na cidade (FREIRE, 1990; NATAL, 2011), verificouse quais espécies são nativas regionais. Foram verificadas a distribuição das espécies e possíveis endemismos com base na Lista de Espécies da Flora do Brasil (FORZZA et al., 2010). As espécies potencialmente invasoras foram identificadas de acordo com informações do Instituto Hórus de Desenvolvimento e Conservação Ambiental (INSTITUTO HÓRUS, 2011). Também foram identificadas algumas espécies potencialmente nocivas à saúde humana (SOUZA et al., 2011; DÍEZ-GÓMEZ et al.,1998). 
Em todos os exemplares analisados foram tomados dados de altura geral (estimativa), altura da primeira bifurcação, diâmetro da copa (contando o diâmetro da sombra, no horário entre 11 e 13h) e DAP, medidos com trena métrica.

\section{RESULTADOS E DISCUSSÃO}

Na arborização das principais vias de Petrópolis, um total de 206 indivíduos vivos (arbóreos, arbustivos, coníferas e palmáceas) foi inventariado, perfazendo 38 espécies, 35 gêneros e 17 famílias, sendo Fabaceae a família mais representativa, com $32,5 \%$ do total, e o jambeiro (Syzygium malaccense) a espécie mais frequente, com 20,9\%

(Tabela 1).

TABELA 1. Espécies, valores de frequências absoluta $(\mathrm{N})$ e relativa (\%) e características ecológicas encontrados no levantamento florístico de quatro logradouros no bairro de Petrópolis, Natal/RN, 2010. E = espécie exótica; N = nativa do Brasil, exceto da região de estudo; $\mathrm{R}=$ espécie nativa regional; $\mathrm{B}=$ endêmica do $\mathrm{Brasil}$; $\mathrm{I}=$ potencialmente invasora; $\mathrm{T}=$ potencialmente nociva à saúde humana.

\begin{tabular}{|c|c|c|c|c|c|}
\hline Família & Nome científico & Nome comum & $\mathbf{N}$ & $\%$ & Características \\
\hline \multirow[t]{2}{*}{ Anacardiaceae } & Anacardium occidentale $\mathrm{L}$. & Cajueiro & 8 & 3,9 & $\mathrm{~N}, \mathrm{R}$ \\
\hline & Mangifera indica L. & Mangueira & 5 & 2,4 & E, I \\
\hline \multirow[t]{3}{*}{ Apocynaceae } & Nerium oleander L. & Espirradeira & 3 & 1,5 & E, T \\
\hline & Plumeria pudica Jacq. & Buquê de Noiva & 1 & 0,5 & $\mathrm{E}$ \\
\hline & Plumeria rubra L. & Jasmim Manga & 2 & 1,0 & $\mathrm{E}, \mathrm{T}$ \\
\hline Araucariaceae & $\begin{array}{l}\text { Araucaria columnaris (Forst.) } \\
\text { Hook. }\end{array}$ & Pinheiro & 1 & 0,5 & E \\
\hline \multirow[t]{2}{*}{ Arecaceae } & $\begin{array}{l}\text { Livistona chinensis (Jacq.) R. Br. ex } \\
\text { Mart. }\end{array}$ & Palmeira de Leque & 5 & 2,4 & $\mathrm{E}$ \\
\hline & $\begin{array}{l}\text { Roystonea oleracea (Jacq.) O. F. } \\
\text { Cook }\end{array}$ & Palmeira Imperial & 1 & 0,5 & $\mathrm{E}$ \\
\hline \multirow[t]{2}{*}{ Bignoniaceae } & Handroanthus albus (Cham.) Mattos & Ipê amarelo & 1 & 0,5 & $\mathrm{~N}$ \\
\hline & $\begin{array}{l}\text { Tabebuia aurea (Silva Manso) } \\
\text { Benth. \& Hook. f. ex S. Moore }\end{array}$ & Craibeira & 2 & 1,0 & $\mathrm{~N}$ \\
\hline Casuarinaceae & $\begin{array}{l}\text { Casuarina equisetifolia J. R. \& G. } \\
\text { Forst. }\end{array}$ & Casuarina & 1 & 0,5 & E, I \\
\hline Chrysobalanaceae & Licania tomentosa (Benth.) Fritsch & Oitizeiro & 9 & 4,4 & $\mathrm{~N}$ \\
\hline Combretaceae & Terminalia catappa $\mathrm{L}$. & Castanhola & 17 & 8,3 & E, I \\
\hline \multirow[t]{5}{*}{ Fabaceae } & Adenanthera pavonina L. & Carolina & 26 & 12,6 & $\mathrm{E}$ \\
\hline & Caesalpinia echinata Lam. & Pau-Brasil & 2 & 1,0 & $\mathrm{~N}, \mathrm{~B}, \mathrm{R}$ \\
\hline & Cassia fistula $\mathrm{L}$. & Acácia & 1 & 0,5 & $\mathrm{E}$ \\
\hline & Clitoria fairchildiana Howard & Sombreiro & 2 & 1,0 & $\mathrm{~N}$ \\
\hline & \multicolumn{5}{|c|}{ ANÁLISE DA ARBORIZAÇÃO VIÁRIA DO... } \\
\hline
\end{tabular}




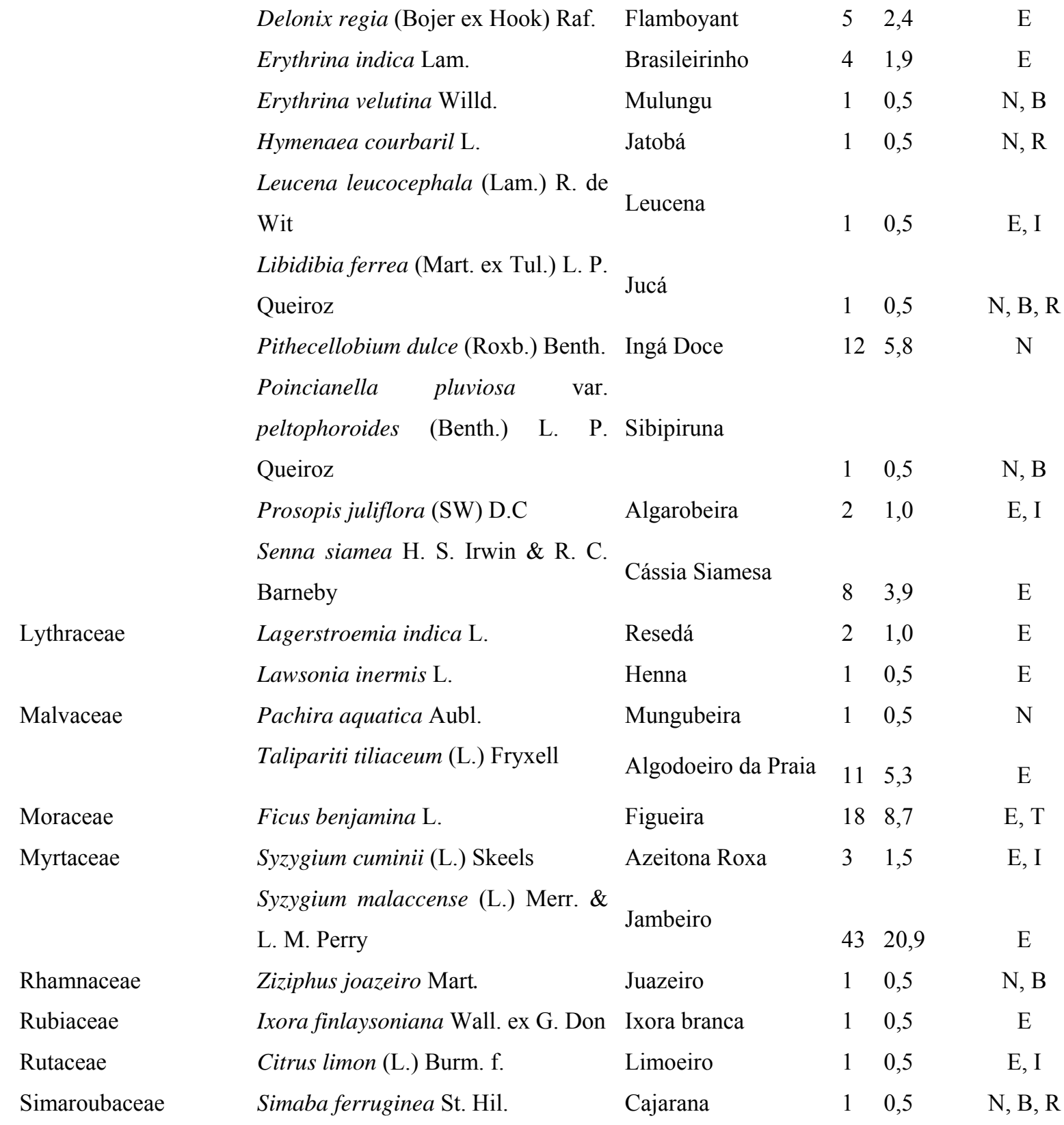

Quanto à abundância das espécies utilizadas na arborização viária, verificou-se que as quatro predominantes correspondem a 50,5\% de toda a arborização analisada. Os dados percentuais da abundância poderão modificar-se no futuro, visto que outras espécies de diferentes hábitos de crescimento (arbóreo, conífera e palmácea) como Anacardium occidentale, Cocos nucifera e
Aracauria columnaris foram plantadas recentemente.

De acordo com Santamour Júnior (2002) é necessário que se adquira uma elevada diversidade de árvores na paisagem urbana para que seja assegurado o máximo de proteção contra pragas e doenças. $\mathrm{O}$ autor recomenda que o número de espécies não exceda mais de $10 \%$ do total, o de gêneros mais de $20 \%$ e de famílias mais de $30 \%$. 
Apenas duas espécies excederam os $10 \%$ recomendado: Syzygium malaccense, com 20,9\%, e Adenanthera pavonina, com 12,6\%.

Observou-se o uso de espécies potencialmente nocivas, como Plumeria rubra, Nerium oleander e Ficus benjamina, essa última frequentemente utilizada no paisagismo e arborização em todo o país, inclusive em Natal, apesar do contato com seu látex poder causar rinite alérgica e asma em pessoas com hipersensibilidade (DÍEZ-GÓMEZ et al., 1998). Tais espécies são, portanto, desaconselhadas para o plantio em vias públicas.

Em relação à origem, as espécies exóticas detêm $63,2 \%$ de representação (79,1\% dos indivíduos) e as nativas $36,8 \%$ (20,9\% dos indivíduos). Dentre estas últimas, cinco espécies $(13,1 \%)$ são nativas regionais, com um quantitativo de 13 indivíduos (6,4\% do total). Espécies como Jucá, Pau-brasil e Cajarana são recomendadas para plantio por ocorrem na flora regional e serem endêmicas do Brasil. A predominância de espécies exóticas nas vias de Petrópolis corrobora com os resultados obtidos por Macêdo et al. (2012) para o Campus Central da UFRN onde o seu predomínio sobre as nativas causa preocupações relacionadas à disseminação dessas espécies em uma Unidade de Conservação próxima (Parque Estadual Dunas de Natal, localizado na ZPA 2), e a uma maior susceptibilidade às pragas e doenças locais, o que requer custos mais elevados para a manutenção e controle da arborização.

Cestaro (2003) sugere uma lista de 38 espécies regionais com potencial para arborização urbana em Natal, com ocorrência registrada nas proximidades da cidade e distribuição pelas florestas brasileiras ou são endêmicas da Mata Atlântica, seguindo como critério as características de persistência das folhas, frutos apreciados pela fauna, cor da flor e espaço adequado ao porte. Macêdo et al. (2012) também sugerem uma relação com 33 espécies que ocorrem nos biomas Caatinga e Mata Atlântica do RN para serem utilizadas na arborização do Campus Central da UFRN com base nas características de persistência das folhas, peso do fruto, conformação da copa e altura máxima. Embora tais estudos levem em conta um reduzido número de características de seleção de espécies, outras peculiaridades - algumas difíceis de avaliar num primeiro momento - podem ser utilizadas, como a tolerância a poluentes e às baixas condições de aeração do solo; presença de odores; tempo de crescimento e de longevidade; época e duração do florescimento e frutificação; resistência a pragas e doenças; sistema radicular profundo e pivotante; tronco único, sem espinhos; dimensão da copa; tronco e ramos consistentes; folhas pilosas, cerosas ou espinhosas que absorvam gases poluentes e prendam partículas sobre sua superfície; ausência de toxicidade e princípios alergênicos, dentre outras (SANTAMOUR JÚNIOR, 2002; MARTO et al., 2006). Segundo Isernhagen et al. (2009), muitas das características listadas são desejáveis, embora discutíveis, para a definição das espécies nativas a serem utilizadas na arborização urbana.

A falta de conhecimento das características das espécies nativas regionais e do seu comportamento em ambientes urbanos é o principal desafio para sua utilização na arborização urbana, pois nem sempre apresentam um bom desempenho, sendo necessário avaliar a adaptabilidade dessas ao ambiente urbano (HARRIS et al., 1999). Alcançar esse objetivo demandará uma intensa colaboração entre pesquisadores e gestores urbanos, sendo importante a comunicação e o envolvimento com a população local. 
Segundo Bortoleto (2004), as árvores do meio viário estão constantemente interagindo com outras espécies, propiciando maior sustentabilidade ao ecossistema. Brun et al. (2007) destacam a importância da arborização urbana como forma de manutenção da biodiversidade, principalmente em relação a avifauna e entomofauna. $\mathrm{Na}$ arborização viária analisada, verificaram-se diversas interações ecológicas, sendo mais frequente com formigas, musgos, fungos, líquens e cupins (Figura 2). Observou-se também a incidência de aves, lagartos e morcegos, além de ninhos, casulos e posturas de répteis. Apesar dos trechos analisados apresentarem fluxo constante de veículos, as diversas interações observadas expressam a importância da arborização para a manutenção da biodiversidade local, fornecendo abrigo, local de reprodução e alimentação para várias espécies.

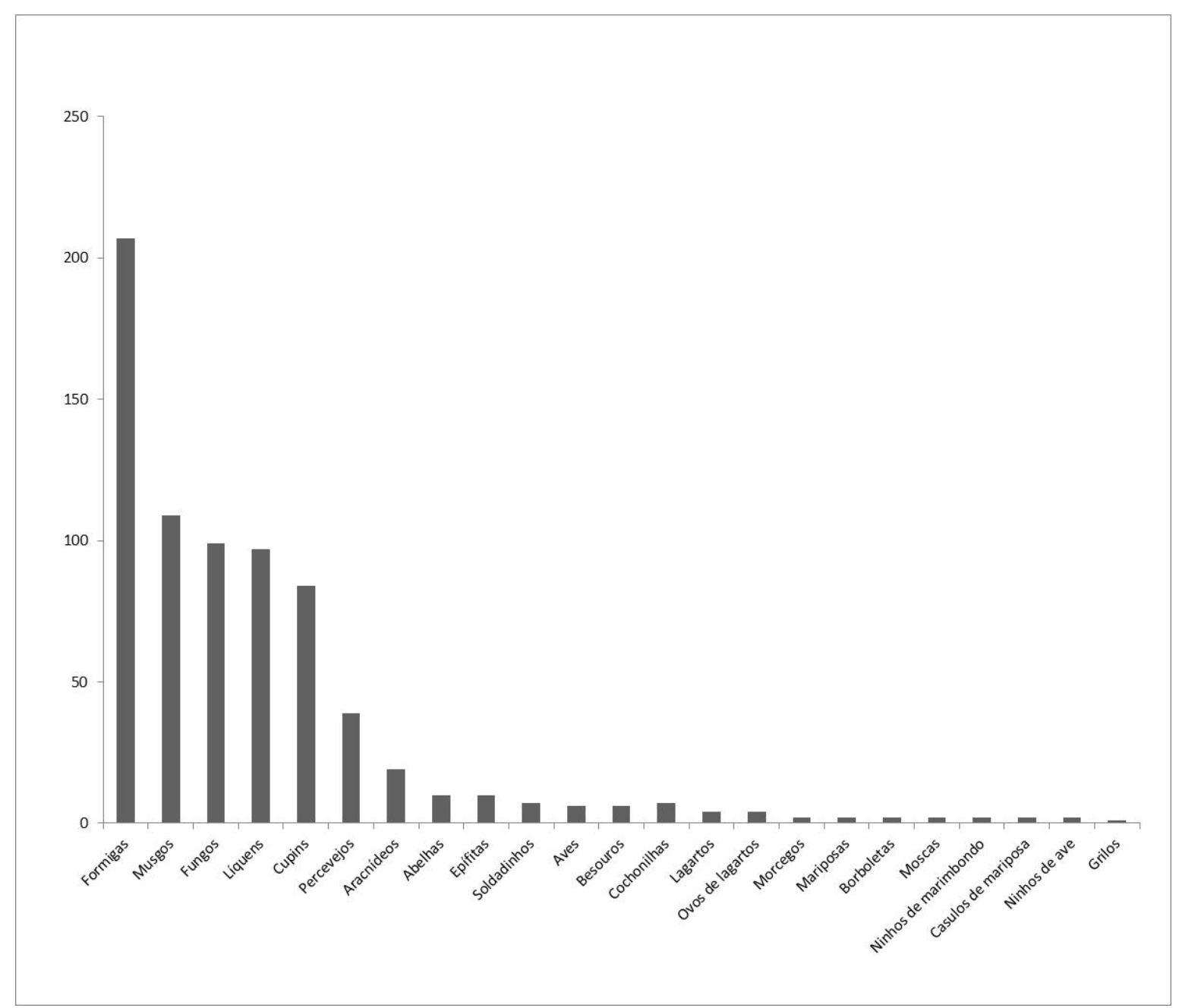

FIGURA 2. Interações ecológicas na arborização viária do Bairro de Petrópolis, Natal/RN.

Macrolíquens (ELIASARO et al., 2009) e musgos (ONIANWA, 2001) podem ser considerados bioindicadores de qualidade do ar. O macrolíquens foram observados em 97 dos espécimes analisados (Tabela 1), distribuídos dentre 23 espécies da arborização viária (Tabela 2). De forma semelhante, 
os musgos foram encontrados em 109 árvores de 12 espécies. Por ocorrerem com frequência e abrangerem uma boa amplitude de espécies, os líquens e musgos são uma boa fonte de estudos de qualidade ambiental para o bairro.

Quanto às aves e seus ninhos que, segundo

Bortoleto (2004), são indicadores da vida em comunidade, verificaram-se poucas interações (Tabelas 1 e 2), assim como em relação às abelhas que, segundo Brun et al. (2007), desempenham um papel dos mais importantes na manutenção da biodiversidade.

TABELA 2. Espécies da arborização viária e seus respectivos bioindicadores de qualidade ambiental em quatro vias no bairro de Petrópolis, Natal/RN, 2010.

\begin{tabular}{|c|c|c|c|c|c|}
\hline \multirow{2}{*}{ Espécies da arborizaçãoviária } & \multicolumn{5}{|c|}{ Indicadores de Qualidade } \\
\hline & Ninhos de aves & Musgos & Líquens & Aves & Abelhas \\
\hline Adenanthera pavonina & & $\mathrm{x}$ & $\mathrm{x}$ & $\mathrm{x}$ & $\mathrm{x}$ \\
\hline Anacardium occidentale & & $\mathrm{x}$ & $\mathrm{x}$ & & $\mathrm{x}$ \\
\hline Caesalpinia echinata & & & $\mathrm{x}$ & & \\
\hline Cassia fistula & & & $\mathrm{x}$ & & \\
\hline Citrus limon & & & $\mathrm{x}$ & & \\
\hline Clitoria fairchildiana & & & $\mathrm{x}$ & & \\
\hline Erythrina indica & & & $\mathrm{x}$ & & \\
\hline Erythrina velutina & & & $\mathrm{x}$ & & \\
\hline Ficus benjamina & & $\mathrm{x}$ & $\mathrm{x}$ & $\mathrm{x}$ & $\mathrm{x}$ \\
\hline Ixora finlaysoniana & & $\mathrm{x}$ & & & \\
\hline Lawsonia inermis & & & $\mathrm{x}$ & & \\
\hline Licania tomentosa & & $\mathrm{x}$ & $\mathrm{x}$ & $\mathrm{x}$ & \\
\hline Mangifera indica & & & $\mathrm{x}$ & & \\
\hline Nerium oleander & & $\mathrm{x}$ & $\mathrm{x}$ & & \\
\hline Pithecellobium dulce & $\mathrm{x}$ & $\mathrm{x}$ & $\mathrm{x}$ & & \\
\hline Plumeria pudica & & & & & $\mathrm{x}$ \\
\hline Plumeria rubra & & & $\mathrm{x}$ & & \\
\hline Prosopis juliflora & & & $\mathrm{x}$ & & \\
\hline Roystonea oleraceae & & & $\mathrm{x}$ & & \\
\hline Senna siamea & & $\mathrm{x}$ & $\mathrm{x}$ & $\mathrm{x}$ & \\
\hline Syzygium cuminii & & $\mathrm{x}$ & $\mathrm{x}$ & & \\
\hline Syzygium malaccense & & $\mathrm{x}$ & $\mathrm{x}$ & & $\mathrm{x}$ \\
\hline Tabebuia aurea & & $\mathrm{x}$ & $\mathrm{x}$ & $\mathrm{x}$ & \\
\hline Talipariti tiliaceum & & & $\mathrm{x}$ & & $\mathrm{x}$ \\
\hline Terminalia catappa & $\mathrm{x}$ & $\mathrm{x}$ & $\mathrm{x}$ & & \\
\hline
\end{tabular}


Um total de 3,07 $\mathrm{km}$ de ruas e avenidas do bairro de Petrópolis foi percorrido (Tabela 3). Desse total, $0,27 \mathrm{~km}$ correspondem a trechos que não apresentaram árvores, geralmente por não conterem canteiros centrais e, quando sim, eram estreitos ou cimentados. Embora o trecho da via Marechal
Deodoro da Fonseca que corta o bairro não ser o mais extenso, seu maior índice de indivíduos $/ \mathrm{km}$ pode ser justificado por ser uma das vias mais antigas do bairro e, portanto, possuir mais contribuições de plantios ao longo dos anos.

TABELA 3. Dados da arborização das principais vias do bairro de Petrópolis, Natal/RN.

\begin{tabular}{lccccc}
\hline \multicolumn{1}{c}{ Vias Públicas } & $\begin{array}{c}\text { Comprimento } \\
(\mathbf{m})\end{array}$ & $\begin{array}{c}\mathbf{N}^{\mathbf{0}} \mathbf{d e} \\
\text { Indivíduos }\end{array}$ & $\begin{array}{c}\text { Índice de } \\
\text { indivíduos/Km }\end{array}$ & $\begin{array}{c}\mathbf{N}^{\mathbf{0}} \mathbf{d e} \\
\text { espécies }\end{array}$ & $\begin{array}{c}\text { Índice de } \\
\text { espécies/Km }\end{array}$ \\
\hline Marechal Deodoro da & & & & & 11 \\
Fonseca, Av. & 875 & 75 & 85,7 & 11,6 \\
Mipibu, R. & 1211 & 59 & 48,7 & 23 & 19,0 \\
Prudente de Morais, Av. & 490 & 29 & 59,2 & 10 & 20,4 \\
Nilo Peçanha, Av. & 490 & 43 & 87,8 & 15 & 30,6 \\
Médias & $\mathbf{7 6 6 , 5}$ & $\mathbf{5 1 , 5}$ & $\mathbf{7 0}$ & $\mathbf{1 4 , 7 5}$ & $\mathbf{2 0 , 6}$ \\
\hline
\end{tabular}

Obteve-se um índice médio de 70 indivíduos $/ \mathrm{km}$ (Tabela 3), valor este mais elevado do que os obtidos em cidades como Manaus, com 20 árvores/km (COSTA e HIGUSHI, 1999), Campos do Jordão, com 17,22 árvores/km (ANDRADE, 2002) e orla marítima do Município de Santos, com 38,93 árvores/km (MENEGHETTI, 2003). Apesar de Petrópolis apresentar um índice de arboriz: 100 viária expressivo, que pode ser justificado pelo fato de ser um dos poucos bairros de Natal que teve Plano de Urbanização projetado para se obter ruas largas e arborizadas, deve-se ressaltar que este trabalho considerou também arbustos, assim como Bortoleto (2004) para a Estância de Águas de São Pedro-SP, que obteve, todavia, um índice médio de arborização mais elevado: 130 indivíduos $/ \mathrm{km}$.

A condição física geral da maioria dos indivíduos cadastrados situou-se entre boa e ótima. Obteve-se 87 (41,0\%) indivíduos em ótimo estado; 73 (34,4\%) em bom estado; 30 (14,2\%) em estado regular; 16 (7,5\%) em péssimo estado; e, seis $(2,8 \%)$ mortos.

Constatou-se práticas de vandalismo em 47 (22,8\%) dos espécimes vivos analisados. No Campus da UFRN, Macêdo et al. (2012) associam a baixa ocorrência de vandalismo à faixa etária e ao nível educacional da população que circula no local. No caso de Petrópolis, embora ocorra predominância de uma população com elevado nível educacional (NATAL, 2010), deve-se levar em consideração que as vias analisadas passam por um centro comercial onde há maior frequência de transeuntes com diferentes faixas etárias e níveis educacionais.

Quanto aos danos físicos, verificaram-se lesões graves em 14,6\% dos indivíduos, lesões médias em $8,3 \%$ e lesões leves em 19,4\%. A respeito do desequilíbrio, provocado geralmente pela reação compensatória do vegetal a podas que desrespeitam seu modelo arquitetônico - formando brotos ladrões de rápido crescimento - ou a uma falta condução da 
muda, $46,1 \%$ o apresentaram no caule, na copa ou em ambos.

De modo geral, os espécimes são de baixo porte, dificilmente atingindo $10 \mathrm{~m}$, sendo algumas espécies arbustivas. Apenas cinco espécies arbóreas possuem a altura mínima recomendada por Costa e
Higuchi (1999) para a primeira bifurcação ou ponto de inversão morfológica, que é de 1,88 m (Tabela 4). A falta de poda de condução, o plantio de mudas arbóreas de pequeno porte ou de arbustos nas vias acarretam dificuldades ao livre trânsito de pedestres.

TABELA 4. Médias dos dados quantitativos das espécies usadas na arborização viária do bairro de Petrópolis, Natal/RN, com amplitudes das espécies com mais de um indivíduo entre parênteses.

\begin{tabular}{|c|c|c|c|c|}
\hline Nome Comum & $\begin{array}{c}\text { Altura Geral } \\
\text { (m) }\end{array}$ & $\begin{array}{c}\text { Altura da } 1^{\text {a }} \text { bifurcação } \\
\text { (m) }\end{array}$ & $\begin{array}{l}\text { Diâmetro da copa } \\
\text { (m) }\end{array}$ & DAP (m) \\
\hline Acácia & 4,86 & 0,48 & 4,76 & 0,37 \\
\hline Algarobeira & $1,60(1,27-1,94)$ & $1,68(1,6-1,77)$ & 0,28 & $0,63(0,26-1)$ \\
\hline Algodoeiro de praia & $4,33(1,72-7,78)$ & $0,66(0,07-2)$ & $5,6(2,52-8,68)$ & $0,44(0,07-1,11)$ \\
\hline Azeitona Roxa & $6,48(3,73-8,1)$ & $1,72(1,04-2,14)$ & $7,67(3,08-12,32)$ & $0,74(0,26-1,5)$ \\
\hline Brasileirinho & $4,04(3,07-5,18)$ & $1,06(0,76-1,5)$ & $5,11(3,08-8,4)$ & $0,52(0,33-0,86)$ \\
\hline Buquê de Noiva & 8,1 & 0,65 & 13,44 & 0,09 \\
\hline Cajarana & 3,24 & 0,75 & 0,72 & 0,11 \\
\hline Cajueiro & $4,86(2,11-7,61)$ & $1,28(0,04-3,56)$ & $6,44(2,8-10,08)$ & $0,86(0,07-2,01)$ \\
\hline Carolina & $8,07(4,54-9,72)$ & $2,16(0,38-3,35)$ & $13,46(2,8-19,04)$ & $1,60(0,38-2,49)$ \\
\hline Cássia Siamesa & $4,52(2,11-8,1)$ & $1,7(0,46-2,14)$ & $5,91(1,96-11,48)$ & $0,82(0,53-1,38)$ \\
\hline Castanhola & $7,13(3,08-10,37)$ & $2,51(0,36-5,5)$ & $9,64(2,8-18,2)$ & $1,54(0,18-4)$ \\
\hline Casuarina & 2,27 & 1,38 & 1,4 & 0,08 \\
\hline Craibeira & $6,72(4,86-8,59)$ & $1,73(1,57-1,9)$ & $8,82(6,72-10,92)$ & $0,66(0,45-0,87)$ \\
\hline Espirradeira & $5,08(3,24-6,48)$ & $1,1(0,55-1,7)$ & $5,6(4,2-6,44)$ & $0,2(0,09-0,26)$ \\
\hline Figueira & $6,34(2,75-9,23)$ & $1,46(0,02-8,1)$ & $7,53(0,84-16,24)$ & $1,48(0,15-3,67)$ \\
\hline \multicolumn{5}{|c|}{ ANÁLISE DA ARBORIZAÇÃO VIÁRIA DO... } \\
\hline
\end{tabular}




\begin{tabular}{|c|c|c|c|c|}
\hline Flamboyant & $3,97(3,24-5,51)$ & $2,1(1,42-2,9)$ & $7,9(5,6-11,76)$ & $1,34(1,16-1,8)$ \\
\hline Henna & 2,27 & 1,44 & 5,6 & 0,26 \\
\hline Ingá Doce & $8,45(6,16-11,32)$ & $1,43(0,57-2,14)$ & $12,57(6,72-17,92)$ & $1,56(0,87-2,8)$ \\
\hline Ipê Amarelo & 2,43 & 1,27 & 4,2 & 0,18 \\
\hline Ixora branca & 3,24 & 1,13 & 3,36 & 0,09 \\
\hline Jambeiro & $6,92(2,92-9,4)$ & $2,11(0,65-12,18)$ & $7,75(0,56-11,2)$ & $1,06(0,15-2,04)$ \\
\hline Jasmim Manga & $2,67(2,43-2,92)$ & $0,11(0,06-0,17)$ & $3,22(0,84-5,6)$ & $0,14(0,14-0,15)$ \\
\hline Jatobá & 7,78 & 1,54 & 4,2 & 0,15 \\
\hline Juazeiro & 3,24 & 0,36 & 7,28 & 1,6 \\
\hline Jucá & 1,5 & 1,2 & 1,68 & 0,07 \\
\hline Leucena & 4,54 & 1,02 & 8,4 & 0,27 \\
\hline Limoeiro & 3,24 & 1,13 & 3,36 & 0,08 \\
\hline Mangueira & $5,41(4,2-9,07)$ & $0,78(0,49-1,19)$ & $6,94(4,2-11,2)$ & $0,44(0,18-0,82)$ \\
\hline Mulungu & 4,54 & 1,8 & 6,16 & 0,46 \\
\hline Mungubeira & 6,97 & 3,08 & 10,64 & 2,83 \\
\hline Oitizeiro & $7,66(4,86-8,75)$ & $1,76(1-3,24)$ & $10,95(5,6-13,16)$ & $1,74(0,63-2,85)$ \\
\hline $\begin{array}{c}\text { Palmeira em } \\
\text { leque }\end{array}$ & $4,11(3,24-4,86)$ & - & $3,75(3,08-4,2)$ & $0,56(0,42-1,03)$ \\
\hline Palmeira Imperial & 7,94 & - & 10,36 & 1,46 \\
\hline Pau Brasil & $2,02(1,94-2,11)$ & $1,02(0,64-1,4)$ & $2,1(1,4-2,8)$ & $0,10(0,06-0,15)$ \\
\hline Pinheiro & 2,75 & 1,52 & 1,68 & 0,11 \\
\hline Resedá & 2,75 & 0,26 & 4,9 & 0,10 \\
\hline
\end{tabular}


Sibipiruna

Sombreiro

Quanto às interferências nas infraestruturas, constatou-se que $15,5 \%$ apresentaram contato com rede de fiação elétrica ou telefônica e 9,7\% apresentaram potencial contato com essas redes. Quanto à iluminação pública, observou-se que 4,9\% dos indivíduos obstruíam a iluminação e $0,5 \%$ apresentaram potencial de obstrução. Em relação ao posteamento, $1,5 \%$ dos indivíduos apresentaram contato atual.

Não foram observadas interferências em sinalizações de tráfego, mas foi constatado que $5,4 \%$ dos indivíduos apresentavam ramos baixos, dificultando a passagem dos veículos. Constatou-se também que a largura média dos canteiros centrais das vias analisadas foi de $3,14 \mathrm{~m}$ e que $17 \%$ dos indivíduos inventariados causavam danos ao calçamento. Os danos causados às calçadas e canteiros pelo crescimento do sistema radicular podem ser prevenidos através de estudos de composição, estrutura e manejo do solo urbano, que influenciam expressivamente o comportamento do sistema radicular (ROSO, 1994).

Embora a arborização do bairro tenha apresentado poucos conflitos arbóreos com as estruturas físicas urbanas, o estabelecimento de critérios de seleção de mudas e de plantio é fundamental para evitar inconformidades. Dentre esses, cita-se o tamanho mínimo da altura e do DAP; área livre permeável para adubação e percolação da água; plantio da muda perpendicular ao solo; mudas isentas de pragas, injúrias ou doenças; dentre outros. Soluções alternativas que permitem a compatibilidade com os sistemas de mobilidade e ocupação territorial são a construção de corredores de ônibus, ciclovias e viadutos; o incentivo ao uso de transporte coletivo ao invés da redução dos canteiros centrais; e, a adoção de medidas de compensação ambiental para cada tipo de ocupação territorial, conforme o tamanho da área de intervenção.

Constatou-se que 49,5\% dos indivíduos necessitam de podas de manutenção e 30,1\% dos indivíduos apresentaram ações de podas, sendo que destas, $13,6 \%$ foram consideradas inadequadas. As práticas inadequadas de podas, principalmente para manutenção dos ramos da copa que entram em contato com a rede de fiação aérea, podem ser evitadas através do plantio de espécies de médio a pequeno porte e o isolamento ou proteção da fiação elétrica. Essa técnica já vem sendo adotada por outros municípios com sucesso (FARHAT e MARÓSTICA, 1994). Também podem ser feitas modificações na disposição dos fios, dos postes e dos sistemas de iluminação pública ou a utilização da fiação subterrânea ao invés da aérea que, embora demande um investimento inicial dez vezes maior que o da rede convencional (VELASCO, 2003 apud BORTOLETO, 2004), é vantajoso em longo prazo e oferece um satisfatório estado geral das árvores. O uso de postes alimentados por energias solar, eólica ou híbridos também é uma opção ainda custosa, mas vem se tornando cada vez mais viável. A falta de poda de manutenção e de controle de pragas nas vias reflete a carência de funcionários e verbas destinadas para a arborização, corroborado pelos resultados obtidos por Cândida (2007) para a manutenção das praças de Natal-RN. A falta de um 
Plano de Arborização para a cidade, a escassez e deficiência no manejo das áreas verdes e o fato de a região metropolitana estar passando por um intenso crescimento imobiliário acarretam em grandes perdas da cobertura vegetal. Essa situação tende a se agravar se não for implantada uma política eficaz para manutenção dos exemplares arbóreos, ampliação e reposição da cobertura perdida ao longo de anos.

\section{CONCLUSÕES}

Tendo em vista os resultados obtidos, conclui-se pela necessidade do estabelecimento de diversas diretrizes e propostas de manejo da arborização viária do bairro de Petrópolis, que também poderão ser estendidas ao manejo da flora de toda a cidade.

Quanto aos mecanismos de gestão, é necessário o fomento de programas de parceria público-privada para a construção e manutenção dos espaços verdes, como forma de compensação ambiental. Sugere-se também que, nos mecanismos de valoração econômica, o fato de ser uma espécie nativa regional gere aumento no respectivo valor, conforme observado por Ramalho e Pimenta (2010). Esse deve ser tanto maior quanto mais rara for a espécie, mais difícil a obtenção de mudas e maior o grau de ameaça de extinção.

O uso de espécies exóticas deve ser restringido em relação às espécies nativas regionais. É fundamental, portanto, fomentar a reestruturação dos viveiros municipais para incorporar maior riqueza dessas espécies e em quantidade adequada. Os prestadores de serviços de manutenção deverão ser instruídos a sobre as características dessas espécies.

A educação ambiental necessita fazer parte do Plano de Arborização a fim de evitar práticas de vandalismo e de sensibilizar a população quanto à importância da arborização. Deve-se abolir a prática cultural de levantamento de copa e podas drásticas para evitar o contato da copa com a rede de fiação aérea. Para isso, pode ser oferecida uma lista de medidas alternativas com seus respectivos custos.

Nas vias próximas a locais onde se realizam eventos e festivais periódicos, responsáveis por atrair turistas, é interessante que seja valorizado na arborização viária espécies nativas regionais cuja floração coincida com a época de realização dos festivais.

É importante que os resíduos gerados com a roçagem sejam aproveitados para compostagem, a fim de se obter uma gestão sustentável da arborização urbana.

O Plano de Arborização deve abranger todas as áreas verdes, reconhecendo as particularidades funcionais de cada uma, e deve estar integrado aos sistemas de gestão urbana. $\mathrm{O}$ uso do geoprocessamento é de fundamental importância no gerenciamento da arborização urbana, podendo ser uma excelente ferramenta para fiscalizar áreas verdes e acompanhar transformações na estrutura da malha urbana.

A execução das diretrizes necessita de uma infraestrutura especializada, permanente e gerenciada por uma instituição pública ou em parceria público-privada. Essas diretrizes precisam passar por atualizações periódicas para acompanhar as inovações tecnológicas e as modificações nas leis vigentes que tratam da gestão urbana, como o próprio Plano Diretor. 


\section{REFERÊNCIAS}

ANDRADE, T. O. Inventário e análise da arborização viária da Estância Turística de Campos do Jordão-SP. Dissertação (Mestrado). Piracicaba: Escola Superior de Agricultura Luiz de Queiroz, Universidade de São Paulo, 2002. 112p.

BIONDI, D.; LEAL, L. Caracterização das plantas produzidas no Horto Municipal da Barreirinha-Curitiba/PR. Revista da Sociedade Brasileira de Arborização Urbana, v.3, n.2, p. 20-36, 2008.

BORtoleto, S. Inventário Qualiquantitativo de Arborização Viária da Estância de Águas de São Pedro-SP. Dissertação (Mestrado). Piracicaba: Escola Superior de Agricultura Luiz de Queiroz, Universidade de São Paulo, 2004. 99p.

BRUN, F. G. K.; LINK, D.; BRUN, E. J. O emprego da arborização na manutenção da biodiversidade de fauna em áreas urbanas. Revista da Sociedade Brasileira de Arborização Urbana, v.2, n.1, p 117-127, 2007.

CÂNDIDA, D. K. As Praças e a Parceria Público-Privada em Natal-RN. Dissertação (Mestrado). Natal: Programa de Pós-Graduação e Pesquisa em Geografia da UFRN, 2008. 136 p.

CESTARO, L. A. Árvores nativas para a arborização de Natal, RN. Congresso Nordestino de Ecologia, X. Recife-PE, 2003. CD-ROM.

COSTA, L. A. C.; HIGUCHI, N. Arborização de ruas de Manaus: avaliação qualitativa e quantitativa. Revista Árvore, v.23, n.2, p.223-232, 1999.

DÍEZ-GÓMEZ, M. L.; QUIRCE, S.; ARAGONESES, E.; CUEVAS, M. Asthma caused by Ficus benjamina latex: Evidence of cross-reactivity with fig fruit and papain. Annals of Allergy, Asthma \& Immunology, v.80, n.1, p.24-30, 1998.

ELIASARO, S.; VEIGA, P. W.; DONHA, C. G.; NOGUEIRA, L. Inventário de macroliquens epífitos sobre árvores utilizadas na arborização urbana em Curitiba, Paraná, Brasil: Subsídio para biomonitoramento urbano. Biotemas, v.22, n.4, p.1-8, 2009.

FARHAT, C. B.; MARÓSTICA, L. M. F. O planejamento urbano levando em consideração a arborização e as áreas verdes: Experiências de Maringá-PR. In: Congresso Brasileiro de Arborização Urbana, 2; Encontro Nacional sobre Arborização Urbana, 5. Anais... São Luiz: Sociedade Brasileira de Arborização Urbana, 1994. p.103-112.

FORZZA, R. C.; LEITMAN, P. M.; COSTA, A. F.; CARVALHO JR., A. A.; PEIXOTO, A. L.; WALTER, B. M. T.; BICUDO, C.; ZAPPI, D.; COSTA, D. P.; LLERAS, E.; MARTINELLI, G.; LIMA, H. C.; PRADO, J.; STEHMANN, J. R.; BAUMGRATZ, J. F. A.; PIRANI, J. R.; SYLVESTRE, L.; MAIA, L. C.; LOHMANN, L. G.; QUEIROZ, L. P.; SILVEIRA, M.; COELHO, M. N.; MAMEDE, M. C.; BASTOS, M. N. C.; MORIM, M. P.; BARBOSA, M. R.; MENEZES, M.; HOPKINS, M.; SECCO, R.; CAVALCANTI, T. B.; SOUZA, V. C. Lista de Espécies da Flora do Brasil 2010. Jardim Botânico do Rio de Janeiro. Disponível em: <http://floradobrasil.jbrj.gov.br/2010/>. Acesso em: 27 dec. 2010.

FREIRE, M. S. B. Levantamento florístico do Parque Estadual das Dunas do Natal. Acta Botanica Brasilica, v.4, p.41-59. 1990.

GREY, G. W.; DENEKE, F. J. Urban forestry. New York: John Wiley, 1978, 279p.

HARRIS, R. W.; CLARK, J. R.; MATHENY, N. P. Arboriculture: integrated management of landscape trees, shrubs, and vines. New Jersey: Prentice Hall, 1999.

INSTITUTO HÓRUS DE DESENVOLVIMENTO E CONSERVAÇÃO AMBIENTAL. Espécies Exóticas Invasoras: Fichas técnicas. Disponível em: $<$ http://www.institutohorus.org.br/index.php?modulo=fichasTecnicas $>$. Acesso em: 27 jun. 2011.

ISERNHAGEN, I.; LE BOURLEGAT, J. M. G.; CARBONI, M. Trazendo a riqueza arbórea regional para dentro das cidades: possibilidades, limitações e benefícios. Revista da Sociedade Brasileira de Arborização Urbana, v.4, n.2, p.117$138,2009$.

LISBOA, C. M. C. A.; CAMPOS, U. M.; SOUZA, S. K. S. Mapeamento e caracterização dos remanescentes de dunas do município de Natal - RN, Brasil. Revista da Sociedade Brasileira de Arborização Urbana, v.6, n.3, p.64-83, 2011. 
LORENZI, H. Árvores brasileiras: manual de identificação e cultivo de plantas arbóreas do Brasil. 4.ed. Nova Odessa: Instituto Plantarum, 2002a. v.1, 384p.

LORENZI, H. Árvores brasileiras: manual de identificação e cultivo de plantas arbóreas do Brasil. 2.ed. Nova Odessa: Instituto Plantarum, 2002b. v.2, 384p.

LORENZI, H.; SOUZA, H. M. de.; TORRES, M. A. V.; BACHER, L. B. Árvores exóticas no Brasil: madeiras, ornamentais e aromáticas. 1.ed. Nova Odessa: Instituto Plantarum, 2003. v.1, 368p.

MACÊDO, B. R. M.; LISBOA, C. M. C. A.; CARVALHO, F. G. Diagnóstico e diretrizes para a arborização do Campus Central da Universidade Federal do Rio Grande do Norte. Revista da Sociedade Brasileira de Arborização Urbana, v.7, n.1, p. 35-51, 2012.

MADRUGADA, P. R. A.; ILlANA, V. B.; KLEINPAUl, J. J.; SCAPINI, G. P.; BERGER, G.; SALBEGO, A. G. Quantificação da cobertura florestal do campus da Universidade Federal de Santa Maria, com o auxílio de imagem de alta resolução. Ambiência, Guarapuava, PR, v.3, n.1, p.79-88, 2007.

MARTO, G. B. T.; BARRICHELO, L. E. G.; SILVA FILHO, D. F.; MULlER, P. H. Arborização Urbana. 2006. Disponível em: http://www.infobibos.com/Artigos/ArborizacaoUrbana/ArborizacaoUrbana.htm. Acesso em: 28 nov. 2008.

MEDEIROS, L. S. M.; DANTAS, I. C. Danos causados ao patrimônio público e particular na cidade de Campina Grande/PB por espécies indevidamente utilizadas na arborização urbana. Revista de Biologia e Farmácia, v.1, n.1, p.37-46, 2007.

MENEGHETTI, G. I. P. Estudo de dois métodos de amostragem para inventário da arborização de ruas dos bairros da orla marítima do município de Santos, SP. Dissertação (Mestrado). Piracicaba: Escola Superior de Agricultura Luiz de Queiroz da Universidade de São Paulo, 2003. 100p.

MILANO, M. S. Avaliação e análise da arborização de ruas de Curitiba-PR. Dissertação (Mestrado). Curitiba: Universidade Federal do Paraná, 1984. 130p.

MILANO, M. S.; DALCIN, E. Arborização de Vias Públicas. Rio de Janeiro: Light, 2000. 206p.

NATAL. Prefeitura Municipal. Secretaria Municipal de Meio Ambiente e Urbanismo. Diagnóstico ambiental da ZPA-1 e seu entorno. Disponível em: <http://www.natal.rn.gov.br/parquedacidade/paginas/ctd-760.html>. Acesso em: 20 jun. 2011.

NATAL. Prefeitura Municipal. Secretaria Municipal de Meio Ambiente e Urbanismo. Anuário Natal 2010. Natal: Departamento de Informação, Pesquisa e Estatística, 2010, 402p.

ONIANWA, P. C. Monitoring Atmospheric Metal Pollution: A Review of the Use of Mosses as Indicators. Environmental Monitoring and Assessment.v.71, n.1, p.13-50, 2001.

RAMALHO, A. M. Z.; PIMENTA, H. C. D. Valoração econômica do dano ambiental ocasionado pela extração ilegal da orquídea Cattleya granulosa no Parque Natural Dom Nivaldo Monte, Natal/RN. Holos, v.1, n.26, p.62-82, 2010.

REIS, A.; ANJOS, A. dos; BECHARA, F. C. Critérios para a seleção de espécies na arborização urbana ecológica. Sellowia, n. 53-55, p.51-67, 2003.

ROSO, A. L. Influência do sistema radicular de árvores urbanas na pavimentação em vias públicas. In: Congresso Brasileiro de Arborização Urbana, 2.; Encontro Nacional sobre Arborização Urbana, 5., São Luiz, 1994. Anais... São Luiz: Sociedade Brasileira de Arborização Urbana. p.347-352, 1994.

SANTAMOUR JÚNIOR, F. S. Trees for urban planting: diversity unifomity, and common sense. Washington: U.S. National Arboretum, Agriculture Research Service, 2002.

SILVA FILHO, D. F. Banco de dados relacional para cadastro, avaliação e manejo da arborização em vias públicas. Revista Árvore, v.26, n.5, p.629-642, 2002.

SILVA, L. M. Reflexões sobre a identidade arbórea das cidades. Revista da Sociedade Brasileira de Arborização Urbana, Piracicaba - SP, v.3, n.3, p. 65-71, 2008.

SOUZA, A. R. C.; ROBAINA, A. D.; PEITER, M. X.; FERRAZ, R. C.; SCHWAB, N. T.; SOUZA, G. R. C.; PINTO, L. M. Identificação das espécies ornamentais nocivas na arborização urbana de Santiago/RS. Revista da Sociedade Brasileira de Arborização Urbana, Piracicaba - SP, v.6, n.2, p.44-56, 2011. 